\title{
Sintesis Zeolit Dari Abu Layang Dengan Metode Hidrotermal dan Uji Adsorptivitas Terhadap Logam Timbal (Pb)
}

\author{
Rismang $^{1^{*}}$, Syamsidar $\mathrm{HS}^{2}$, Kurnia Ramadani ${ }^{1}$ \\ 1Jurusan Kimia, Fakultas Sains dan Teknologi, UIN Alauddin Makassar \\ ${ }^{2}$ Sekolah Tinggi Agama Islam Negeri Watampone \\ email: risman.ashar@yahoo.co.id
}

\begin{abstract}
Synthesis of zeolite from fly ash obtained from Jeneponto Bosowa energypower plant have been conducted by hydrothermal method. This study was conducted to determine the characteristics of a synthetic zeolite fly ash and synthetic zeolite adsortivitas to metallic lead (Pb). Fly ash which is the main source of silica prepared by the process of concentration variations reflux with $\mathrm{HCl}(2 \mathrm{M} ; 3 \mathrm{M} ; 4 \mathrm{M}$ and $5 \mathrm{M})$. Manufacture of sodium silicate solution by dissolving $\mathrm{NaOH}$ fly ash into the proportion of $10 \mathrm{ml}$ per 1 gram of fly ash. Synthesis process by adding sodium aluminate into a solution of sodium silicate with a ratio of $1: 1$ and then put in an autoclave as a hydrothermal process at a temperature of $120^{\circ} \mathrm{C}$ for 2 hours. Hydrothermal product obtained is characterized by X-Ray Diffraction (XRD) to determine the type and intensity of the zeolite crystals obtained from the synthesis process. XRD analysis results showed the highest intensities are in the process of reflux $5 M$ with type zeolite obtained in the form of zeolite ITQ-34, zeolite $(K, B a)-G, L$, sodalite and alumina-silica minerals such as eucryptit and aluminum oxide. The resulting zeolite able to absorb the metals $\mathrm{Pb}^{2+}$ at $99.04 \%$, which is made with a concentration of $20 \mathrm{ppm}$ of $50 \mathrm{~mL}$ with a mass of 1 gram of zeolite.
\end{abstract}

Keywords: adsorption, fly ash, hydrothermal method, synthetic zeolites, lead.

\section{PENDAhUluan}

Perkembangan industri di Indonesia saat ini semakin pesat. Namun tidak hanya memberikan hal yang bersifat positif akan tetapi juga memberikan dampak buruk berupa limbah sebagai hasil samping dari proses industri itu sendiri. Pembangkit listrik tenaga uap (PLTU) yang terdapat di Jeneponto, Sulawesi Selatan merupakan salah satu contoh industri yang menggunakan batubara sebagai bahan bakar. Dari hasil pembakaran ini akan menimbulkan limbah baik berupa gas maupun padatan. Limbah padatan yang dihasilkan berupa abu layang yang hingga saat ini masih kurang dimanfaatkan (Jumaeri, Astuti \& Lestari., 2007)).

Abu layang mengandung oksida-oksida logam termasuk logam-logam berat dalam jumlah kecil. Oksida utama dari abu layang batubara adalah silika $\left(\mathrm{SiO}_{2}\right)$, alumina $\left(\mathrm{Al}_{2} \mathrm{O}_{3}\right)$ dan besi 
$\left(\mathrm{Fe}_{2} \mathrm{O}_{3}\right)$. Keberadaan komponen silika dan alumina memungkinkan abu layang untuk dapat disintesis menjadi material yang strukturnya mirip dengan zeolit atau dikenal dengan ZLM (zeolite like material) (Mufrodi, Sutrisno \& Hidayat, 2010).

Aktivasi abu layang dengan alkali hidrotermal telah dilakukan oleh para peneliti dengan mengunakan sampel yang berbeda dan untuk berbagai tujuan. Diantaranya untuk sintesis zeolit. Proses alkali hidrotermal dikenal dengan Penambahan basa pada campuran abu layang dengan temperatur yang tinggi. Sintesis hidrotermal dilakukan dalam suhu yang tetap dengan tekanan uap yang rendah yang sesuai dengan tekanan uap larutan yang digunakan. Larutan campuran biasanya mengandung senyawa oksida, hidroksida atau berupa garam dari logam yang menjadi bahan dasar dari sintesis itu yang kemudian dimasukkan dalam autoclave (Jumaerti, et.al., 2009).

Zeolit merupakan suatu kelompok mineral yang dihasilkan dari proses hidrotermal. Bagian pembentuk utama yang membangun struktur mineral zeolit adalah $\mathrm{SiO}_{2}$ dan $\mathrm{Al}_{2} \mathrm{O}_{3}$ yang membentuk tertrahedral dimana setiap atom oksigen berada pada keempat sudutnya. Struktur rangka utama zeolit ditempati oleh atom silikon atau aluminium dengan empat atom oksigen di setiap sudutnya.

Zeolit banyak digunakan sebagai adsorben karena kemampuannya mengadsorbsi dan kapasitas tukar kationnya yang tinggi sehingga dapat digunakan sebagai adsorben untuk pengurangi limbah pencemar (Solikah \& Budi, 2014). Pencemaran lingkungan yang tejadi, biasanya berasal dari limbah industri yang mengandung logam berat. Logam-logam berat ini berasal dari proses-proses yang terjadi dalam suatu industri seperti, metalurgi, pengolahan kulit, pembuatan fungisida, cat dan zat warna tekstil. Ion-ion logam berat dari hasil samping industri tersebut dapat merusak lingkungan dan berbahaya bagi makhluk hidup disekitarnya karena sulitnya terurai baik secara biologi maupun secara kimia (Ma'rifat, et.al., 2014).

Timbal salah satu logam pencemar utama saat ini di lingkungan. Hal ini bisa terjadi karena sumber utama pencemaran timbal adalah dari emisi gas buang kendaraan bermotor maupun industri yang pada proses produksinya menggunakan timbal. Adanya timbal pada komponen lingkungan yaitu air, tanah, dan udara memungkinkan pencemaran menjadi lebih luas (Naria, 2005). Berdasarkan penjelasan yang telah dipaparkan diatas, menjadi suatu latar belakang dalam penelitian sintesis zeolit dari abu layang (fly ash) dan uji adsorptivitas terhadap logam timbal, untuk mengetahui karakteristik zeolit yang dihasilkan dan adsorptivitas terhadap logam timbal.

Al-kimia| Volume 5 Nomor 22017 | 128 
Rismang, Syamsidar HS. \&

Ramadani, K.

\section{METODE PENELITIAN}

Alat

Alat-alat yang digunakan dalam penelitian ini antara lain alat-alat gelas, furnace, autoklaf stainless-steel, Shaker merk Thermo Scientific MAXQ 2000, neraca analitik, oven, pemanas listrik, Atomic Absorption Spektrofotometer (AAS) Varian AA240FS, XRD Shimadzu XRD7000, XRF tipe ARL Quant'X Merk Thermo Scientific dan Grand size.

\section{Bahan}

Bahan-bahan yang digunakan dalam penelitian ini adalah abu layang yang diambil dari PLTU Jeneponto sebagai sumber $\mathrm{SiO}_{2}$ dan $\mathrm{Al}_{2} \mathrm{O}_{3}$, asam klorida $(\mathrm{HCl})$, aquadest $\left(\mathrm{H}_{2} \mathrm{O}\right)$, natrium hidroksida $(\mathrm{NaOH})$ marck, aluminium hidroksida $\left(\mathrm{Al}(\mathrm{OH})_{3}\right)$ marck, kertas watman No. 42, Kertas $\mathrm{pH}$ universal, timbal nitrat $\left(\mathrm{Pb}\left(\mathrm{NO}_{3}\right)_{2}\right)$.

\section{Prosedur Kerja Penelitian}

Prosedur kerja penelitian ini dilakukan dengan beberapa tahap diantaranya adalah:

\section{Preparasi Abu Layang}

Abu layang yang diperoleh dari PLTU Jeneponto, dibilas dengan aquadest. Kemudian abu layang dikeringkan dan diayak menggunakan grand size 100 mesh. abu layang telah diayak dinalisis menggunakan XRF. Abu layang kemudian diaktivasi di dalam furnace pada suhu 600 ${ }^{\circ} \mathrm{C}$ selama 2 jam. Sampel didinginkan kemudian masing-masing 60 gram abu layang dicampurkan dengan $200 \mathrm{~mL}$ asam klorida $(\mathrm{HCl})$ dengan konsentrasi 2, 3, 4 dan 5M dan diaduk dengan waktu kontak 4 jam. Abu layang yang telah diaduk dibilas dengan aquadest $\left(\mathrm{H}_{2} \mathrm{O}\right)$ sampai $\mathrm{pH}$ netral, campuran disaring dan dikeringkan dalam oven pada temperatur $105{ }^{\circ} \mathrm{C}$ selama 8 jam.

\section{Pembuatan Natrium Silikat}

Abu layang yang sudah dipreparasi, masing-masing dilarutkan sebanyak 5 gram dalam 50 $\mathrm{mL} \mathrm{NaOH} 6 \mathrm{M}$. kemudian campuran tersebut dipanaskan pada suhu $90{ }^{\circ} \mathrm{C}$ selama 2 jam.

\section{Pembuatan Natrium Aluminat}

Prosedur ini dilakukan dengan melarutakan $\mathrm{NaOH}$ sebanyak 30 gram dalam $250 \mathrm{~mL}$ aquades dan dipanaskan. Kemudian kedalam larutan $\mathrm{NaOH}$ tersebut ditambahkan 20 gram 
Rismang, Syamsidar HS. \&

Ramadani, K.

$\mathrm{Al}(\mathrm{OH})_{3}$ secara perlahan-lahan sambil diaduk sampai larut seluruhnya. Sehingga terbentuk larutan natrium aluminat.

\section{Sintesis Zeolit}

Sintesis zeolit dilakukan dengan menambahkan larutan natrium aluminat secara perlahanlahan ke dalam larutan natrium silikat. Diaduk selam 4 jam sampai terbentuk gel yang berwarna putih. Gel yang terbentuk dimasukan dalam oven selama 2 jam dengan suhu $120{ }^{\circ} \mathrm{C}$ lalu dimasukan kedalam autoklaf selama 2 jam dengan suhu $120{ }^{\circ} \mathrm{C}$. Padatan yang terbentuk disaring dan dikeringkan dalam oven pada temperatur $105{ }^{\circ} \mathrm{C}$ selama 2 jam. Kemudian zeolit dikaraterisasi untuk mengetahui jenis dan kandungan mineral terdapat didalamnya dengan menggunakan alat XRD.

\section{Uji Adsorptivitas Zeolit Terhadap Logam Timbal}

Sebanyak $50 \mathrm{~mL}$ larutan $\mathrm{Pb} 20$ ppm, dipipet ke dalam Erlenmeyer $250 \mathrm{~mL}$ kemudian ditambahkan zeolit sintetik dengan massa 1 gram lalu di shaker selama 40 menit. Larutan didekantasi dan diambil filtratnya untuk diukur absorbansinya dengan spektroskopi serapan atom (SSA).

\section{HASIL DAN PEMBAHASAN}

Penelitian ini dilakukan dua tahap yaitu dengan melakukan sintesis zeolit dengan variasi konsentrasi 2M; 3M; 4M dan 5M, pada proses refluks abu layang dan kemampuan zeolit sintetik dalam menyerap logam timbal $(\mathrm{Pb})$.

Tabel 1 merupakan hasil analisis XRF pada abu layang yang merupakan analisis pendahuluan sebelum digunakan dalam proses sintesis dengan kandungan utama $\mathrm{SiO}_{2}$ yang kadarnya mencapai $41.96 \%$.

Sintesis zeolit dilakukan dengan beberapa tahap. Tahap pertama adalah pembuatan natrium silikat dilakukan dengan melarutakan abu layang ke dalam $\mathrm{NaOH}$ yang kemudian dipanaskan pada suhu $90{ }^{\circ} \mathrm{C}$ sehingga terbentuk larutan natrium silikat. Natrium silikat merupakan sumber utama silika untuk sintesis zeolit yang reaksi pembentukannya sebagai berikut:

$$
\mathrm{SiO}_{2(\mathrm{~s})}+2 \mathrm{NaOH}_{(\mathrm{l})} \longrightarrow \mathrm{Na}_{2} \mathrm{SiO}_{3(\mathrm{l})}+\mathrm{H}_{2} \mathrm{O}_{(\mathrm{l})}
$$

Al-kimia| Volume 5 Nomor 22017 || 130 
Rismang, Syamsidar HS. \&

Ramadani, K.

Tabel 1. Hasil analis XRF abu layang PLTU Jeneponto

\begin{tabular}{ccc}
\hline No & Komponen & $($ \% berat $)$ \\
\hline 1 & $\mathrm{SiO}_{2}$ & 41.96 \\
2 & $\mathrm{Al}_{2} \mathrm{O}_{3}$ & 10.13 \\
3 & $\mathrm{CaO}$ & 13.76 \\
4 & $\mathrm{TiO}_{2}$ & 0.90 \\
5 & $\mathrm{Fe}_{2} \mathrm{O}_{3}$ & 31.46 \\
6 & $\mathrm{MnO}$ & 0,475 \\
7 & $\mathrm{BaO}$ & 0.253 \\
8 & $\mathrm{SrO}_{2}$ & 0.117 \\
9 & $\mathrm{ZrO}_{2}$ & 0,053 \\
10 & $\mathrm{Nb}_{2} \mathrm{O}_{5}$ & 0,0111 \\
11 & $\mathrm{SnO}_{4}$ & 0,0107 \\
12 & $\mathrm{RuO}_{4}$ & 0.0103 \\
13 & $\mathrm{Sb}_{2} \mathrm{O}$ & 0.0066 \\
\hline
\end{tabular}

Tahap kedua adalah pembuatan natrium aluminat sebagai sumber utama aluminium dalam sintesis zeolit. Proses pembuatan natrium aluminat dilakukan dengan melarutakan aluminium hidriksoda dalam $\mathrm{NaOH}$ dengan reaksi pembentukannya sebagai berikut:

$$
\mathrm{Al}(\mathrm{OH})_{3(\mathrm{~s})}+2 \mathrm{NaOH}_{(\mathrm{l})} \longrightarrow \mathrm{NaAl}(\mathrm{OH})_{4(\mathrm{l})}
$$

$\mathrm{NaOH}$ digunakan sebagai aktivator dalam pembentukan garam silikat dan aluminat. Penambahan $\mathrm{NaOH}$ selain sebagai reagen juga berfungsi sebagai metalizer yang menetralkan muatan negatif yang berlebih pada Aluminium yang terdapat pada zeolit. Selain itu $\mathrm{Na}^{+}$yang terdapat pada $\mathrm{NaOH}$ memiliki peranan penting dalam sintesis zeolit karena kemampuannya dalam menstabilkan unit pembentuk kerangka zeolit (Kristiyani, Susatyo \& Prasetya, 2012).

Tahap selanjutnya adalah sintesis zeolit yang dilakukan dengan menambahkan natrium aluminat ke dalam natrium silikat dengan perbandingan volume 1:1 secara perlahan-lahan kemudian dishaker selama 4 jam sampai terbentuk gel. Gel yang terbentuk di oven selama 2 jam pada suhu $120{ }^{\circ} \mathrm{C}$ sebelum dimasukkan ke autoklaf agar suhu larutan cepat naik. Kemudian Al-kimia| Volume 5 Nomor 22017 || 131 
dihidrotermal dalam autoklaf selama 2 jam dengan suhu $120{ }^{\circ} \mathrm{C}$ untuk pembentukan kristal zeolit. Produk hidrotermal berupa Kristal halus yang kemudian disebut ZS1.2M; ZS2.3M; ZS3.4M dan ZS4.5M.

Pembentukan zeolit terjadi karena adanya proses pelarutan silika dan alumina yang terdapat dalam abu layang membentuk natrium silikat dan natrium aluminat. Larutan tersebut saling bereaksi membentuk senyawa baru berupa kerangka alumina-silika dengan berbagai sisi aktif yang dapat digunakan untuk menjerat ion-ion logam berat. Reaksi pembentukan zeolit secara umum ditunjukkan seperti reaksi berikut:

$$
\mathrm{Na}_{2} \mathrm{SiO}_{3}(\mathrm{aq})+\mathrm{Na}_{2} \mathrm{Al}(\mathrm{OH})_{4}(\mathrm{aq}) \longrightarrow \mathrm{Na}_{\mathrm{x}}\left[\left(\mathrm{AlO}_{2}\right)_{\mathrm{y}}\left(\mathrm{SiO}_{2}\right)_{\mathrm{z}}\right] \cdot h \mathrm{H}_{2} \mathrm{O}
$$

\section{Analisis XRD pada Zeolit Sintetik}

Karakterisasi zeolit dilakukan dengan difraksi sinar X (shimadzu XRD-7000) untuk menentukan ukuran kristal dan jenis mineral yang terkandung didalam sampel yang discan menggunakan radiasi $\mathrm{Cu}$ dengan voltase $40 \mathrm{kV}$ dan arus sebesar $30 \mathrm{~mA}$ dengan rentang sudut $2 \theta$ $\left(15^{\circ}-50^{\circ}\right)$. Data yang diperoleh berupa intesitas dan sudut $(2 \theta)$ yang kemudian dicocokkan dengan data standar pola difraksi sinar-X JCPDS (Joint Committee For Powder diffraction Standar) untuk mengidentifikasi senyawa yang terdapat dalam sampel.

Pola difraksi atau difraktogram zeolit sintetik dapat terlihat pada gambar 3.1 dengan perlakuan variasi konsentrasi pada proses refluks menghasilkan pola yang berbeda. Pola tersebut memperlihatkan adanya perbedaan yang muncul pada ketajaman puncak seiring bertambahnya konsentrasi asam yang digunakan pada proses refluks. Difraktogram tersebut menunjukkan bahwa mineral yang diperoleh dalam sampel sintesis merupakan mineral kristal yang dilihat dari puncak-puncak tajam yang muncul.

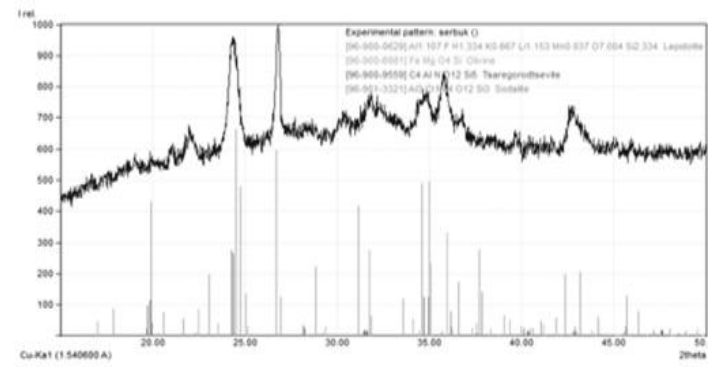

(a)

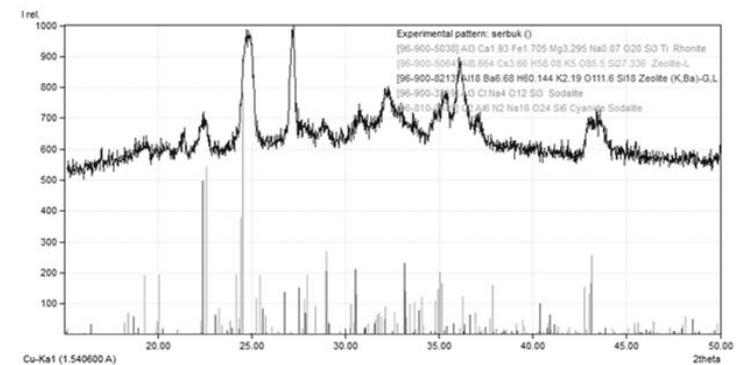

(b)

Al-kimia| Volume 5 Nomor 22017 | 132 


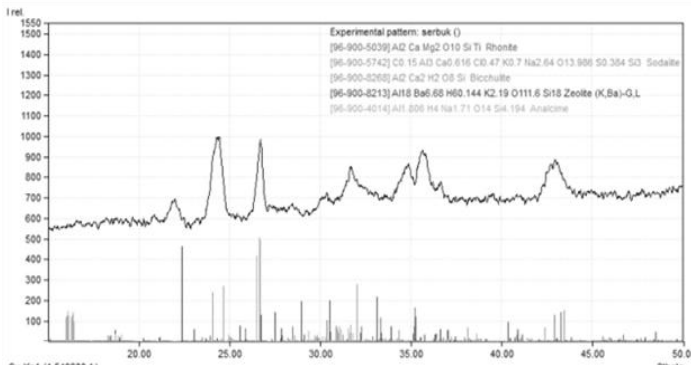

(c)

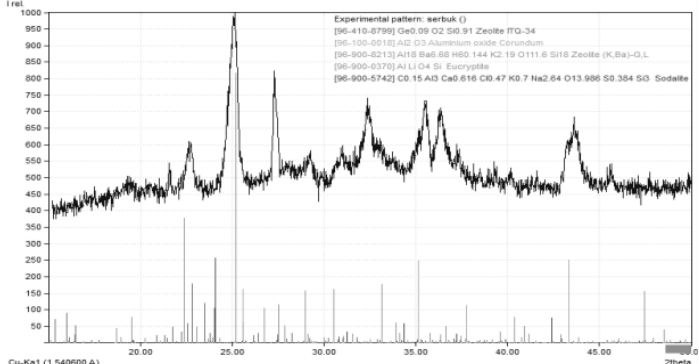

(d)

Gambar 1. Difraktogram zeolit sintetik dengan variasi perendaman $\mathrm{HCl}$ : (a) $2 \mathrm{M}$ (b) $3 \mathrm{M}$ (c) $4 \mathrm{M}$ (d) $5 \mathrm{M}$

Tipe zeolit (K,Ba)-G,L muncul pada refluks 3M; 4M dan 5M dengan intensitas $17.5 \%$; $15.2 \%$ dan $22.6 \%$ data tersebut menunjukkan adanya peningkatan intensitas pada konsentrasi $5 \mathrm{M}$ akan tetapi pada konsentarsi 4M zeolit (K,Ba)-G,L mengalami penurunan intensitas. Hasil sintesis dengan konsentrasi refluks 3M terdapat juga zeolit-L yang sifat dan strukturnya hampir sama dengan zeolit tipe (K,Ba)-G,L. Selain tipe zeolit (K,Ba)-G,L, terdapat pula tipe zeolit ITQ34 pada hasil refluks $5 \mathrm{M}$ dengan intensitas $30.1 \%$ yang merupakan intensitas yang cukup tinggi dibandingkan dengan jenis zeolit (K, Ba)-G,L yang muncul pada 3M; 4M dan 5M sedangkan untuk senyawa sodalit muncul disetiap hasil perlakuan refluks dengan $\mathrm{HCl}$ dengan intensitas berturut-turut $9.2 \% ; 12.8 \% ; 4.2 \%$ dan $7.7 \%$.

Munculnya puncak utama disetiap sudut-sudut tertentu jika diperhatikan secara seksama mengalami pergeseran sudut dari setiap konsentrasi yang digunakan. Perbedaan konsentrasi proses refluks seiring dengan adanya perubahan jenis mineral yang terkandung didalam sampel. Intensitas puncak juga mengalami perubahan dengan meningkatnya kristalinitas senyawa. Namun pada intensitas Kristal zeolit masih tergolong rendah baik pada perlakuan refluks 2M, 3M, 4M maupun 5M, salah satu faktor yang sangat berpengaruh pada pembentukan Kristal zeolit adalah suhu dan waktu hidrotermal.

Semakin tinggi suhu yang digunakan maka intensitas Kristanya jugal akan semakin tinggi. Suhu proses hidrotermal yang tinggi akan meningkatkan jumlah tumbukan antara abu layang dengan $\mathrm{NaOH}$ yang mempercepat dan meningkatkan pembentukan Kristal zeolit. Kenaikan suhu tidak memberikan perubahan produk yang begitu banyak. Kenaikan suhu hanya meningkatkan intensitas fase Kristal dan berkurangnya fase amorf (Jumaeri, dkk, 2009: 28-30).

Waktu hidrotermal juga berpengaruh cukup besar terhadap pembentukan inti dan pertumbuhan Kristal. Disamping itu alat hidrotermal yang digunakan juga memberi pengaruh 
Rismang, Syamsidar HS. \&

Ramadani, K.

dalam pertumbuhan zeolit yang disintesis, dimana tekanan yang tidak konstan menyebabkan suhu dalam proses sintesis tidak stabil sehingga berpengaruh dalam pertumbuhan Kristal (Sholichah, et.al., 2013).

\section{Uji Adsorptivitas Zeolit Terhadap Logam Timbal}

Aplikasi zeolit sintetik dalam meyerap logam timbal yang dibuat dengan konsentrasi 20 ppm dengan volume $50 \mathrm{~mL}$. zeolit yang digunakan untuk adsorpsi dipanaskan agar kadar air yang terdapat dalam pori-pori zeolit menguap. Penguapan air pada zeolit akan memperluas ukuran pori-pori pada zeolit sehingga dalam proses adsorpsi dapat berlangsung efektif.

Tabel 2. Adsorptivitas zeolit sintetik terhadap logam timbal

\begin{tabular}{cccc}
\hline \multicolumn{4}{c}{ Aplikasi untuk adsorpsi Pb } \\
\hline $\begin{array}{c}\text { Konsentrasi awal } \\
\mathrm{Pb}(\mathrm{ppm})\end{array}$ & $\begin{array}{c}\text { Konsentasi akhir } \\
\mathrm{Pb}(\mathrm{ppm})\end{array}$ & $\begin{array}{c}\mathrm{Pb} \text { Teradsorpsi } \\
(\mathrm{ppm})\end{array}$ & $\begin{array}{c}\text { Efisiensi } \\
\text { Penyerapan }(\%)\end{array}$ \\
\hline & & & \\
20 & 0.192 & 19.808 & 99.04 \\
\hline
\end{tabular}

Adsorpsi logam timbal $(\mathrm{Pb})$ menggunakan zeolit sintetik dilakukan untuk mengetahui kemampuan zeolit dalam menyerap logam berat khususnya logam timbal. Namun pada penelitian ini tidak ditentukan kondisi optimal seperti pengaruh $\mathrm{pH}$, konsentarsi, massa adsorben dan waktu kontak karena hanya dilakukan uji adsorptivitas zeolit sintetik terhadap salah satu logam berat yaitu timbal $(\mathrm{Pb})$.

Penentuan adsorptivitas yang dilakukan dalam penelitian ini mengunakan waktu kontak optimum yang dilakukan oleh Kristiyani, et.al. (2012) yaitu 40 menit dengan tingkat efisiensi adsorpsi zeolit mencapai $99.04 \%$ dari nilai tersebut dapat memberikan informasi bahwa zeolit tersebut dapat menyerap logam $\mathrm{Pb}$.

\section{PENUTUP}

\section{Kesimpulan}

Karekteristik zeolit abu layang yang diperoleh dari sintesis metode hidrotermal dengan variasi refluks konsentrasi $\mathrm{HCl}(2 \mathrm{M} ; 3 \mathrm{M} ; 4 \mathrm{M}$ dan $5 \mathrm{M})$ adalah zeolit dengan tingkat kristalinitas yang tinggi. Pada konsentrasi HCl 5M dihasilkan zeolit dengan tipe ITQ-34, Zeolit (K.Ba) G-L, Sodalit dan beberapa jenis mineral alumina-silika seperti eucryptit dan aluminum oksida 
Rismang, Syamsidar HS. \&

Ramadani, K.

corundum. Adsorptivitas Zeolit sintetik abu layang dengan metode hidrotermal sangat efektif sebagai adsorben logam timbal $(\mathrm{Pb})$ dengan tingkat efisiensi sebesar $99.04 \%$.

\section{DAFTAR PUSTAKA}

Jumaeri, W., Astuti, W.T.P. \& Lestari. (2007). Preparasi dan karakterisasi zeolit dari abu layang batubara secara alkali hidrotermal. Reaktor, 11(1), 38-44.

Jumaeri, Sutarno, Kunarti, E.S. \& Santosa, S.J. (2009). Pengaruh konsentrasi naoh dan temperatur pada sintesis zeolit dari abu layang secara alkali hidrotermal. Journal of Indonesia Zeolites. 8(1), 22-32.

Kristiyani, D., Susatyo, E.B. \& Prasetya, A.T. (2012). Pemanfaatan zeolit abu zekam padi untuk menurunkan ion $\mathrm{Pb}^{2+}$ pada air sumur. Indonesian Journal of Chemical Science. 1(1), 1318.

Ma'rifat, Krisdayanto, D., Khamidinal \& Nugraha. I. (2014). Sintesis zeolit dari abu dasar batubara dan aplikasinya sebagai adsorben logam merkuri (II). Molekul. 9(1), 73-83.

Mufrodi, Z, Sutrisno, B. \& Hidayat, A. (2010). Modifikasi limbah abu layang sebagai material baru adsorben. Prosiding Seminar Nasional Teknik kimia (Kejuangan). ISSN 1693 4393, $1-6$.

Naria, E. (2005). Mewaspadai dampak bahan pencemar timbal $(\mathrm{Pb})$ di lingkungan terhadap kesehatan. Jurnal Komunikasi Penelitian. 17(4), 66-72.

Solikah, S \& Utami, B. (2014). Perbedaan penggunaan adsorben dari zeolit alam teraktivasi dan zeolit terimobilisasi dithizon untuk penyerpan ion logam tembaga $\left(\mathrm{Cu}^{2+}\right)$. Seminar Nasional Kimia dan Pendidikan Kimia VI, 342-354.

Sholichah, Fitriani, Arnelli \& Suseno., A. (2013). Pengaruh waktu hidrotermal pada sintesis zeolit dari abu sekam padi serta aplikasinya sebagai builder deterjen. Chem Info. 1(1), 121-129. 